\title{
Deleted Yq in the sterile son of a man with a satellited Y chromosome (Yqs)
}

\author{
A C CHANDLEY, J R GOSDEN, T B HARGREAVE, G SPOWART, \\ R M SPEED, AND S McBEATH \\ From the MRC Human Genetics Unit, and the University of Edinburgh, Department of Surgery (Urology), \\ Western General Hospital, Edinburgh EH4 $2 X U$.
}

SUMMARY Disturbed spermatogenesis and azoospermia are reported in a man with a deleted Y chromosome. The anomalous $\mathrm{Y}$ chromosome appears in the karyotype as a small metacentric marker. In situ hybridisation using three different $Y$ specific DNA probes shows that deletion at Yq11 has resulted in loss of all distal heterochromatin. The sterility of the patient indicates loss also of the azoospermia factor (AZF) located at the Yq distal euchromatic/heterochromatic interface. Microspread and air dried meiotic preparations show a severe impairment of spermatogenesis but rare cells are seen to be progressing to the late prophase stage. The testicular histology shows most of the seminiferous tubules to be completely hyalinised.

The father and a fertile brother of the proband show a satellited Y chromosome (Yqs) in their karyotypes. The case appears to be the first of its kind reported in which a father with a satellited $\mathrm{Y}$ chromosome has produced a son carrying a different $\mathrm{Y}$ chromosome anomaly. The possible derivation of the one from the other is discussed.

Tiepolo and Zuffardi ${ }^{1}$ were the first to postulate the existence of factors controlling spermatogenesis on the distal non-fluorescent portion of the human $\mathrm{Y}$ chromosome long arm. Their evidence was based on six cases of deletion of the $\mathrm{Y}$ chromosome at band q11 in men with a normal phenotype but azoospermia, ascertained at an infertility clinic, and other published cases available at that time. Since then, a number of other deleted and structurally rearranged $\mathrm{Y}$ chromosomes associated with aspermatogenesis have been described, ${ }^{2}{ }^{3}$ lending support to the hypothesis. We now present a further case of sterility resulting from azoospermia in a man with a tiny metacentric non-fluorescent $\mathrm{Y}$ chromosome. In histological section the testes show gross hyalinisation of the seminiferous tubules, although in a few tubules there is a remnant of spermatogenic activity. Microspread and air dried meiotic preparations show limited germ cell development to the pachytene stage of prophase.

Of interest is the fact that the father and a fertile brother of the proband show a satellited Y chromosome (Yqs) in their somatic karyotypes. In situ hybridisation has been used to investigate the nature

Received for publication 12 July 1988

Revised version accepted for publication 16 September 1988. of the $\mathrm{Y}$ chromosome anomalies in all three males using $\mathrm{Y}$ specific DNA probes.

\section{Case report}

The patient, aged 28 years, first attended the male infertility clinic of the Western General Hospital, Edinburgh, in June 1986. He and his partner had been trying for a child for two years. He was a phenotypically normal male and no abnormality which might account for the failure to conceive could be traced to his partner.

The patient's height was $1.76 \mathrm{~m}$ and weight $78 \mathrm{~kg}$. The testes were $12 \mathrm{cc}$ in mean volume (normal range for Caucasians 15 to $45 \mathrm{cc}$ ) and the penis and scrotum were normal. Two semen samples, analysed in June 1985 and April 1986, showed azoospermia.

Raised levels of $\mathrm{LH}$ and FSH were recorded: $\mathrm{LH}$ 9.3 U/l (normal range 1 to $6.5 \mathrm{U} / \mathrm{l}$ ) and FSH $18.6 \mathrm{U} / 1$ (normal range 1 to $6 \mathrm{U} / \mathrm{l})$. Testosterone $(25.3 \mathrm{ng} / \mathrm{ml}$ ) was within the normal range (10 to $30 \mathrm{ng} / \mathrm{ml})$.

Biopsies were taken from both testes in May 1987. The two sides showed essentially the same features, most tubules being completely hyalinised (fig 1 ). In a few tubules there was some remnant of a germinal epithelium in which spermatogonia were present and there was limited meiotic activity. The number 


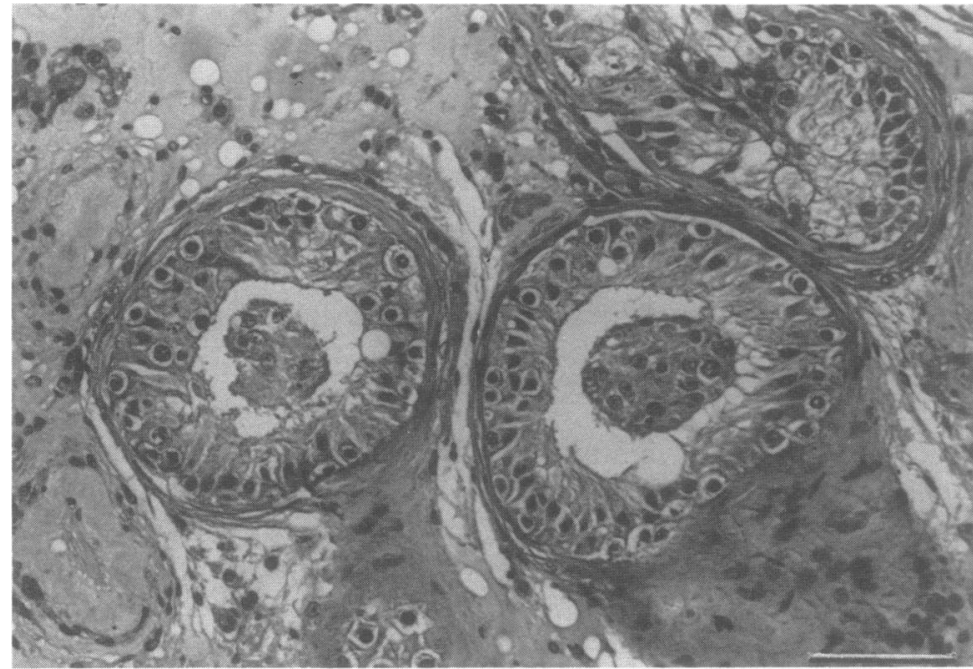

FIG 1 Testicular histology in the proband.

of spermatogonia was much lower, however, on the left side. No spermatids or spermatozoa were seen. There was marked thickening of the tunica propria in most tubules and a marked increase in the intertubular connective tissue. No other features of note were recorded other than minimal hyperplasia of the Leydig cells on the right side.

\section{Materials and methods}

BLOOD LYMPHOCYTE CHROMOSOME ANALYSIS Blood for somatic chromosome analysis was obtained from the proband, his father, and his 30 year old brother who was married with one child. A repeat sample of blood was taken from the proband at the time of testicular biopsy. Conventional Giemsa staining as well as $G,{ }^{4} \mathrm{C},{ }^{5}$ and $\mathrm{R}$ banding ${ }^{6}$ was carried out. In addition, the anomalous $\mathrm{Y}$ chromosome in each of the subjects investigated was analysed by methyl green/DAPI fluorescence, ${ }^{7}$ by silver staining for kinetochores and NORs, ${ }^{8}$ by ammoniacal silver carbonate, ${ }^{9}$ and by spermidene Bis-acridine fluorescence. ${ }^{10}$

MEIOTIC ANALYSIS

Analysis of germ cells from the testicular suspensions of the proband was carried out by air drying ${ }^{11}$ and EM microspreading. ${ }^{12}$

\section{IN SITU HYBRIDISATION}

The preparation of the $Y$ chromosome specific probe pHY $2 \cdot 1$ was described by Cooke et al. ${ }^{13}$ The principal site of hybridisation is to the distal long arm heterochromatin of the $\mathrm{Y}$ chromosome (Yqh).
Probe pDP105 detects a family of $\mathrm{Y}$ specific repeated sequences, most copies being in deletion interval 3 on Yp (pDP105/A), but some being in interval 6 on Yq (pDP105/B). ${ }^{14}$ The probe thus hybridises around the centromeric region of the $\mathrm{Y}$ chromosome. Probe 29A1 hybridises to the Ypter pseudoautosomal region at locus DXYS20 (H J Cooke, 1988, personal communication). Probes were labelled with ${ }^{3} \mathrm{H}$ by nick translation as described by Gosden et al. ${ }^{15}$

Preparations of mitotic chromosomes from the proband, his father, his brother, and a control male with a normal $\mathrm{Y}$ chromosome were denatured in $70 \%$ formamide, $0.6 \times \mathrm{SSC}$, and hybridised overnight at $37^{\circ} \mathrm{C}$ as described previously. ${ }^{15}$ Posthybridisation washes were in $50 \%$ formamide, $2 \times \mathrm{SSC}$, at $42^{\circ} \mathrm{C}(4 \times 5$ minutes $)$ and $2 \times \mathrm{SSC}$ at $42^{\circ} \mathrm{C}$ ( $4 \times 5$ minutes).

Slides were coated with Ilford L4 liquid emulsion mixed 1:1 with distilled water at $45^{\circ} \mathrm{C}$. Exposure was at $4^{\circ} \mathrm{C}$ for seven days for probe phY2.1, seven to 10 days for pDP105, and 21 days for probe 29A1. o Autoradiographs were developed in Kodak D19 and N fixed in Kodafix 1:3 as described previously. ${ }^{15}$ All slides were stained with $5 \%$ Giemsa through the emulsion.

\section{Results}

BLOOD LYMPHOCYTE CHROMOSOME ANALYSIS

The proband

$G$ banding of the somatic chromosomes of the $\stackrel{\mathbb{D}}{2}$ proband showed a complement lacking a normal $\mathrm{Y} \underset{2}{2}$ 

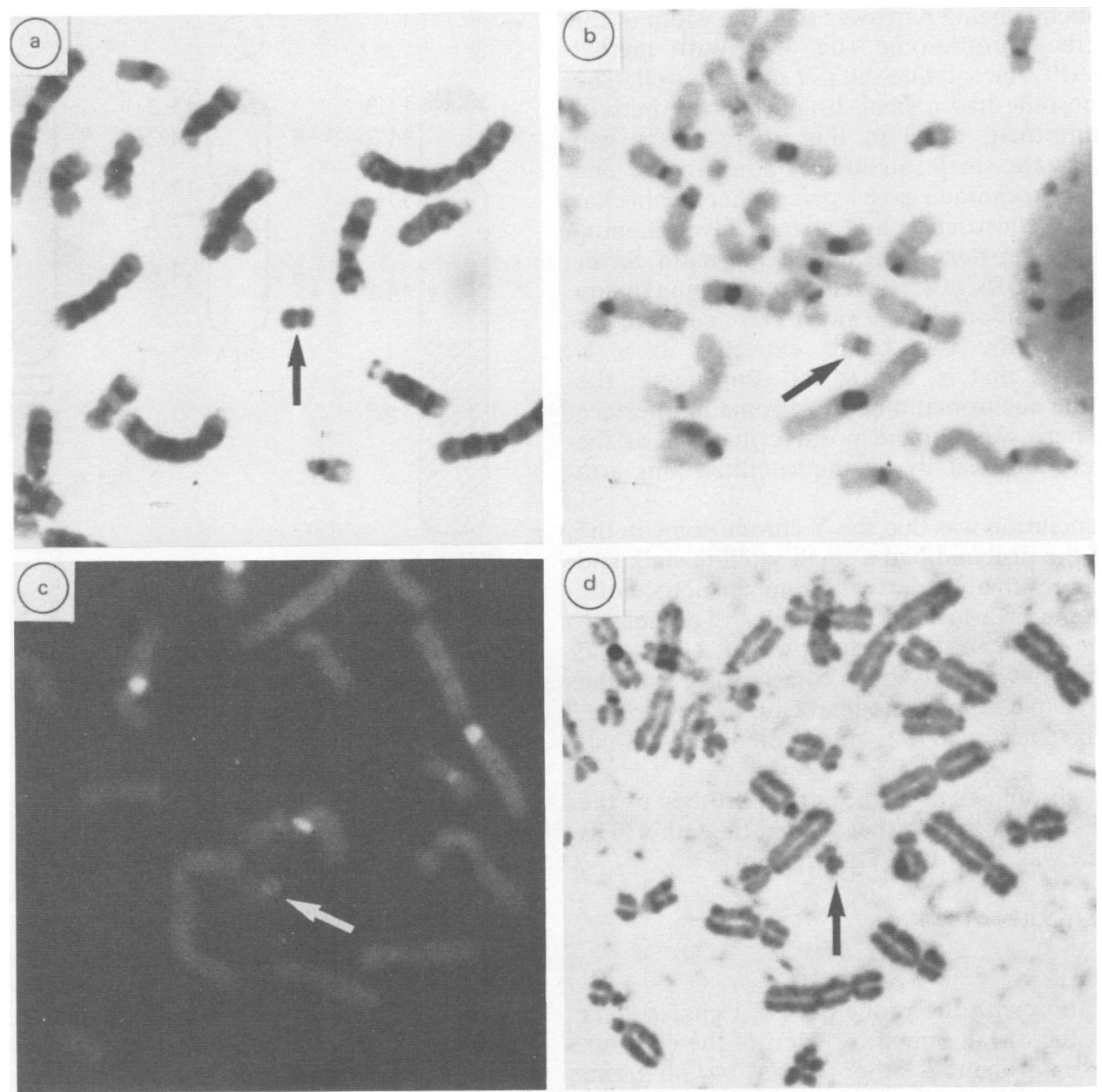

FIG 2 Deleted Y chromosome of the proband (arrowed). (a) G banding, (b) C banding, (c) methyl green/DAPI, (d) ammoniacal silver carbonate staining.

chromosome. A tiny marker, which was present in addition to 45 other normal chromosomes, was assumed to be an anomalous $\mathrm{Y}$ chromosome (fig 2a). In most cells, the marker appeared metacentric, but in a few cells one arm was seen to be slightly longer than the other. The marker showed no non-centromeric heterochromatin by either $\mathrm{C}$ banding (fig $2 \mathrm{~b}$ ) or methyl green/DAPI staining (fig $2 c)$. $R$ banding showed one arm of the marker to be darker than the other, indicating that the abnormal chromosome could be a $\mathrm{Y}$ chromosome deleted in the long arm. ${ }^{16}$ Silver staining showed one obvious pair of kinetochores but no other silver positive structures. One silver positive band was seen at the centromere after ammoniacal silver carbonate stain- ing (fig 2d), but a second band normally shown by this technique ${ }^{9}$ at the euchromatin/heterochromatin interface in the intact $\mathrm{Y}$ chromosome could not be established in the small marker chromosome of the proband. From the staining studies, it was concluded that the marker chromosome was a deleted $\mathrm{Y}$ chromosome, deletion having occurred in band Yq11.2. The karyotype thus appeared to be $46, X$, $\operatorname{del}(Y)(p t e r \rightarrow q 11.2)$. (fig 3a).

\section{Father of the proband}

$G$ banding of the somatic chromosomes of the proband's father showed that satellites were present on the distal tip of the Y chromosome long arm (fig $4 a)$. With $(\mathrm{CMA})_{2} \mathrm{~S}$ this satellite region was bright 
and distinctive being narrower than the width of the rest of the chromosome (fig $4 \mathrm{~b}$ ). With methyl green/DAPI, the satellite did not show up well. The Y chromosome had a small bright band of heterochromatin, then, distal to this, there was a gap followed by the small satellited region (fig $4 \mathrm{c}$ ). The kinetochore technique gave a pair of kinetochores at the primary constriction and a small silver staining region in the gap next to the heterochromatin. Silver staining for NORs gave a small silver staining region in the gap mentioned. The silver carbonate technique showed the two bands expected in a Y chromosome, that is, one at the centromere, the other at the euchromatin/heterochromatin interface in Yq. There was $\mathrm{C}$ band positive material at the centromere and distally on the satellited long arm (fig 4d).

The conclusion was that the $\mathrm{Y}$ chromosome in the father of the proband had a small satellite stalk and satellite, presumably derived from an acrocentric chromosome translocated onto Yqh. ${ }^{17}$ The heterochromatic region on $\mathrm{Yq}$ was, however, small, and part of it may well have been translocated onto the $\mathrm{D}$ or $\mathrm{G}$ group chromosome by reciprocal rearrangement. The karyotype was interpreted as $46, \mathrm{XYqs}$ (fig 3b).

The Y chromosome in the fertile brother of the proband was identical to that seen in the father. His karyotype was also 46,XYqs (fig 3b).

\section{IN SITU HYBRIDISATION}

\section{Probe pHY 2.1}

Hybridisation with the probe $\mathrm{pHY} 2 \cdot 1$ gave a clear signal on the distal long arm region of the chromosome of the proband's father (fig 5a) but no grains were seen on the small marker chromosome of the proband in any cell (fig 5b), indicating loss of Yqh. Some label was seen on the acrocentric short arms both in the proband and his father. The presence of satellites on the distal long arm of the Y chromosome in the father caused association with the acrocentrics to occur in many cells (fig 5a), and it was, as expected, always the labelled end of the $Y$ chromosome which was in contact. Associations with acrocentrics did not occur for the marker $\mathrm{Y}$ of the proband. Labelling with probe pHY $2 \cdot 1$ was not performed on the chromosomes of the proband's brother.

\section{Probe pDP105}

A total of 100 somatic metaphases was analysed in the proband after in situ hybridisation with the probe pDP105. Eighty-four percent of cells showed conspicuous labelling over the marker chromosome, the range of counts for the marker after a seven day

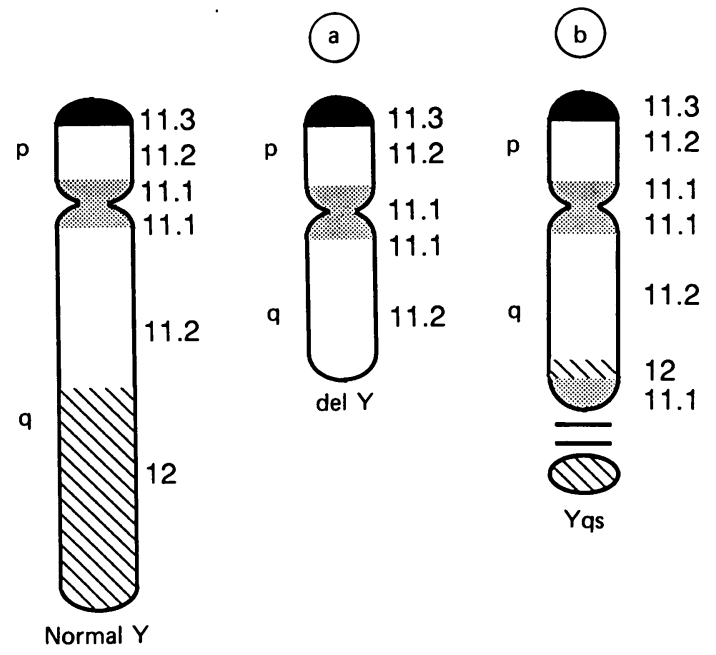

FIG 3 Diagrammatic representation of (a) the deleted $Y$ (del $Y$ ) of the proband and $(b)$ the satellited $Y(Y q s)$ of his father and fertile brother. A normal Y chromosome is shown for comparison.

exposure period being 0 to 25 grains (mean count $=$ two grains). Usually, the grains were seen to be disposed around the centromere or slightly more towards one of the arms (fig 6a). Good labelling around the centromere was also achieved with this probe hybridised to the father's (fig $6 \mathrm{~b}$ ) and brother's (fig 6c) somatic Y chromosomes and also to that of the control male. Disposition of grains towards the Y short arm was apparent in cells with more elongated chromosomes (fig 6c). Association of the Yq satellites to acrocentrics was also seen, the end furthest away from the labelled site being always the one associating (fig 6b). The clear hybridisation of probe pDP105 to the small marker chromosome in the proband gave conclusive proof that this was indeed a $\mathrm{Y}$ chromosome.

\section{Probe 29A1}

Of 100 somatic metaphases from the proband hybridised with the Yp telomeric probe 29A1, 27\% showed labelling of one to three grains over the distal tips of one of the arms after a 21 day exposure (fig 6d). In the cell shown, it was clearly the shorter arm (Yp) which was labelled, as expected for this probe.

MEIOTIC ANALYSIS IN THE PROBAND The suspension of testicular cells used in the air dried analysis showed mainly Sertoli cells with a very few spermatogonial metaphases and prophase spermatocytes up to the late pachytene stage. No 

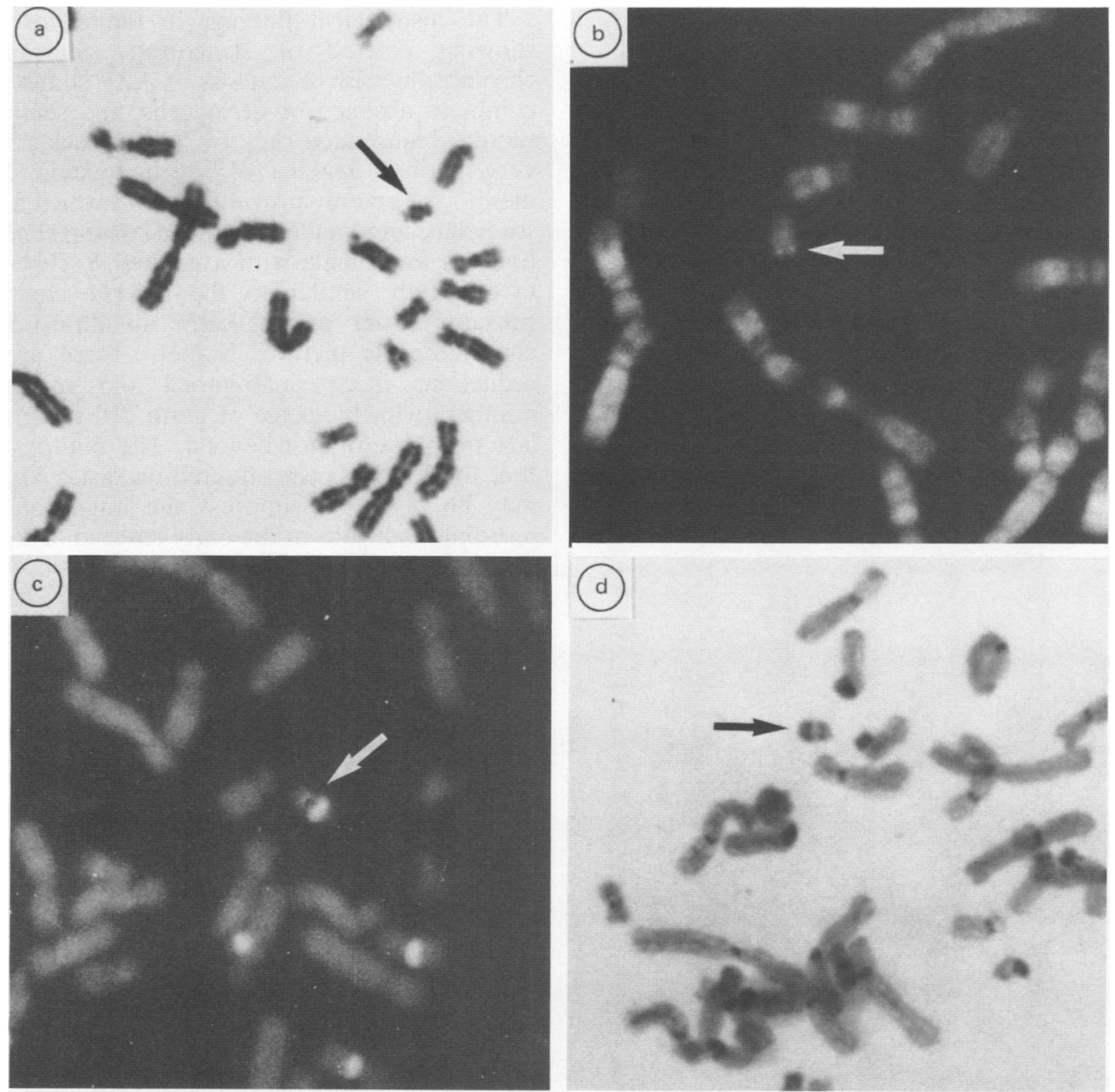

FIG 4 Satellited $Y$ chromosome of the father of the proband (arrowed). (a) G banding, (b) $(C M A)_{2} S$ staining, (c) methyl green/DAPI, (d) C banding.

later meiotic stages were found. In total, for five slides prepared from the right testis, only 11 spermatogonial metaphases and nine pachytenes were found. Pachytene spermatocytes would occur in abundance in a normal preparation.

A total of $15 \mathrm{EM}$ grids was examined, on which only 16 prophase spermatocytes were found. Of these, 10 showed unassociated sex chromosomes and six showed the sex chromosomes to be paired. Among the 10 cells with unpaired sex chromosomes, eight showed the axis of the small marker Y to be self paired, either in the form of a hairpin or a balloon (fig 7a). For the six cells showing paired sex chromosomes, the axis of the marker $\mathrm{Y}$ was self paired in a hairpin in four cells (fig $7 b$ ), the remainder showing the $\mathrm{Y}$ axis as a normal rod. A number of examples of asynapsis within the autosomal complement of synaptonemal complexes was also observed, but this is not uncommon among the germ cells of patients with arrested spermatogenic development. ${ }^{18}$

\section{Discussion}

By the combined use of staining techniques and DNA probe analysis, the abnormal chromosome marker in the karyotype of the proband has been interpreted to be a deleted Y chromosome. Deletion has occurred at a point on the long arm, in band q11, resulting in loss of all heterochromatin detectable by 


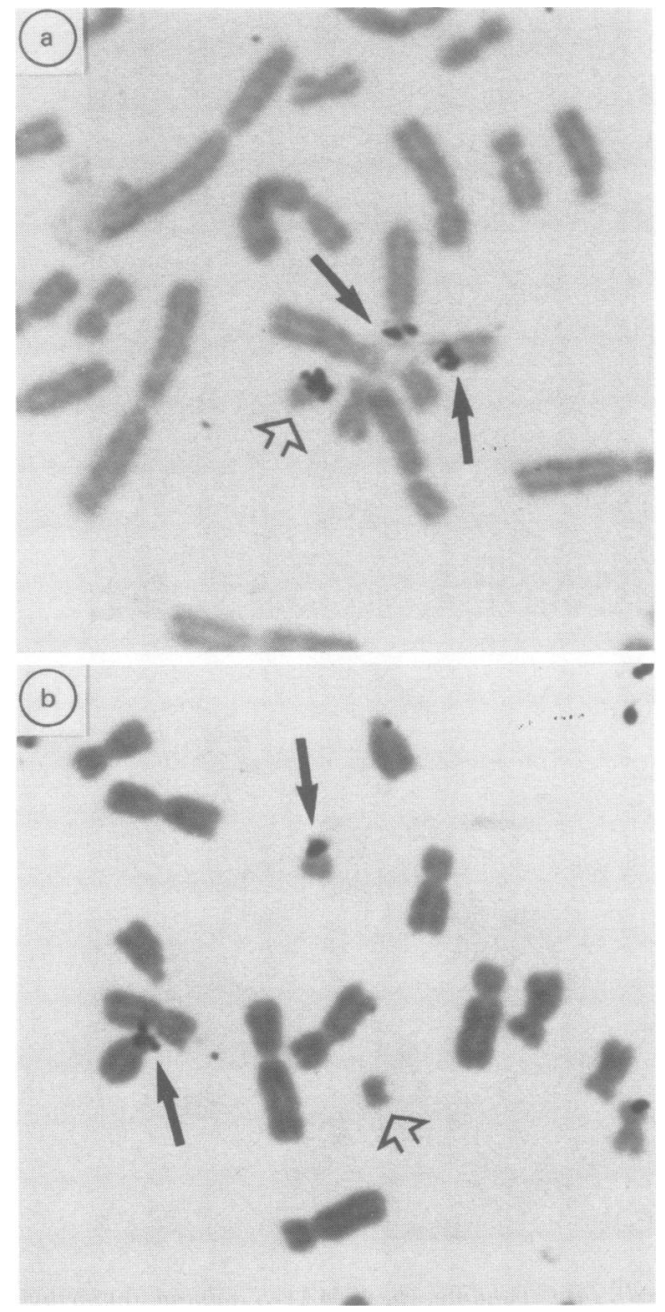

FIG 5 In situ hybridisation using probe pHY 2.1 to (a) the father's Y chromosome, (b) the deleted Y chromosome of the proband (open arrows). Long arrows indicate secondary sites of labelling on acrocentric short arms. See text for further detail.

C banding, fluorescence staining, and in situ hybridisation with probe $\mathrm{pHY} 2 \cdot 1$. Moreover, the sterility of the patient, resulting from severe disturbance of spermatogenesis, indicates that loss of the gene controlling fertility (AZF) ${ }^{1}$ has also been deleted. Recent molecular investigations have mapped this 'azoospermia factor' to interval 6 in distal Yq11. ${ }^{19}$ The normal stature of the proband would suggest, however, that the postulated gene for height situated just proximal to the azoospermia factor ${ }^{20}$ has not been deleted.
The histological findings in the testes of men showing deleted or structurally rearranged $\mathrm{Y}$ chromosomes involving loss of AZF shows either a complete absence of germ cells, the seminiferous tubules being lined only by Sertoli cells, ${ }^{122122}$ or very limited degrees of spermatogenic development. ${ }^{323}$ The only previous case in which a meiotic study has been made is that of Hartung et al. ${ }^{3}$ Their findings for a male with a deleted $\mathrm{Y}$ chromosome cytologically similar to the marker chromosome present in our patient show an almost identical spermatogenic picture. Namely, there are severe reductions in spermatogonial and spermatocyte numbers with blockage of germ cell maturation at late prophase or just beyond. The findings suggest that the fertility gene situated on distal $\mathrm{Yq}$ in man may be acting to suppress the migration of primordial germ cells in the early embryo or to restrict the proliferation of spermatogonial cells in the adult testis. Germ cell maturation arrest before $\mathrm{MI}$ is also noted for the few spermatocytes which may proceed through prophase.

The behaviour of the $\mathrm{Y}$ chromosome at meiotic prophase in the proband, as shown in the spread pachytenes, is of some interest, as the majority of cells showed a self paired $\mathrm{Y}$ axis both in cells with attached $\mathrm{X}$ and $\mathrm{Y}$ chromosomes and those with unpaired sex chromosome axes. A possible explanation ${ }^{18}$ is that the marker in the proband is in fact an iso-Yp rather than a Y deleted at q11, the self paired structure arising out of the homologous synapsis of two identical short arms. A strong tendency for self pairing in the $\mathrm{Y}$ axis has been observed in XY, Sxr mice ${ }^{24}$ and in this situation it was suggested that self pairing was initiated between the two homologous testis determining regions carried on the $\mathrm{Y}$ chromosome of these males. Hairpin formations can, however, be observed in univalent axes in a variety of situations $\mathrm{s}^{25}$ and self $₹$ pairing within the $\mathrm{Y}$ axis in the proband need not $\mathrm{O}$ therefore necessarily imply that the $\mathrm{Y}$ chromosome is an isochromosome. Our initial belief, based on the somatic chromosome appearance, could still hold true, namely that the marker is a deleted Y $O$ chromosome.

It is also of interest that the father and brother of the proband carry a satellited $\mathrm{Y}$ chromosome. According to Schmid et al,${ }^{17}$ three types of satellited $\mathrm{Y}$ chromosome occur: some in which no $\mathrm{C}$ band heterochromatin has been lost from distal $\mathrm{Yq}$, one $\stackrel{\mathcal{D}}{\rightarrow}$ rare case in which all fluorescent heterochromatin 7 has been lost, and others where a small remaining 0 band of heterochromatin exists proximal to the $\mathbb{\mathbb { D }}$ satellite. The latter would appear to be the situation $\frac{}{\mathrm{D}}$ in the father and brother of our patient. It seems $\frac{\varrho}{\sigma}$ more than coincidence that the proband in this 


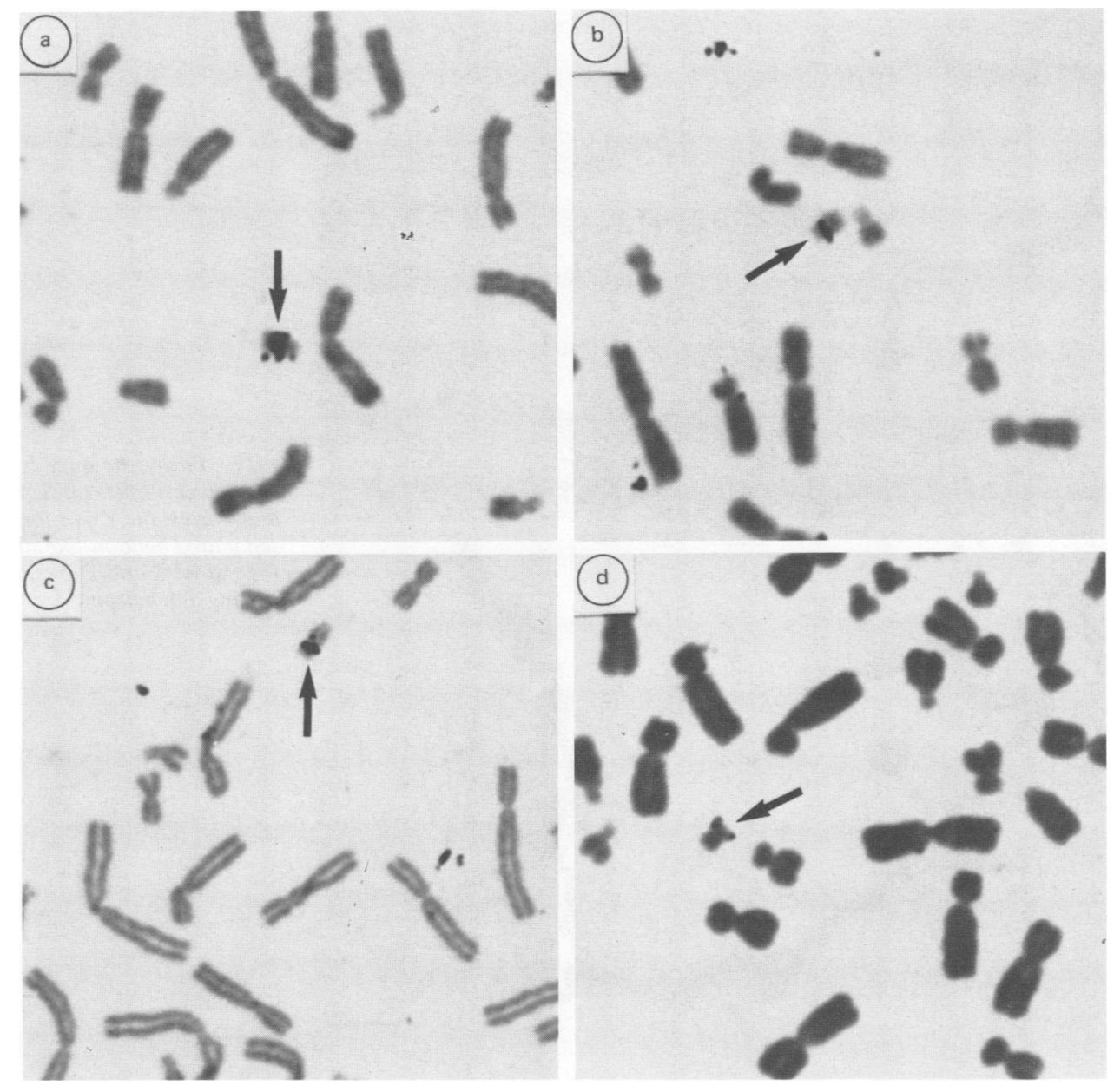

FIG 6 (a-c) In situ hybridisation using probe pDP105. (a) The proband, (b) father of the proband, (c) brother of the proband. (d) In situ hybridisation using probe $29 A 1$ to the deleted $Y$ chromosome of the proband. See text for further detail.

family also carries a structural anomaly in his $\mathrm{Y}$ chromosome, albeit different to that seen in the father. The mechanism by which the deleted $Y$ of the proband could have arisen from the satellited $Y$ of his father is, however, not readily explicable. One simple possibility is that the $\mathrm{Y}$ chromosome of the father has become broken in band q11.2 in a cell of the germline, perhaps owing to stress placed upon it when held in association with the $D$ and $G$ group acrocentrics. The presence of satellites on the long arm of the $\mathrm{Y}$ chromosome in the father would tend to increase the frequency with which such associations occurred in his spermatocytes. Stahl et al, ${ }^{26}$ have shown that $\mathrm{Y}$-acrocentric associations are found in about $10 \%$ of zygotene and pachytene human spermatocytes, the NOR usually being close to the XY pair. These relationships, they believe, could explain the frequent involvement of acrocentrics in $\mathrm{Y}$;autosome translocation, as for example of the kind which has produced the Yqs seen in the father of our patient.

The origin of the satellites on the $\mathrm{Y}$ chromosome of the proband's father has not been investigated, but from a review of published cases it would appear that Yqs chromosomes most frequently arise by reciprocal translocation between Yqh and the short arms of acrocentric chromosomes 15 and $22 .{ }^{17}$ This, it is thought, is because very similar or identical 


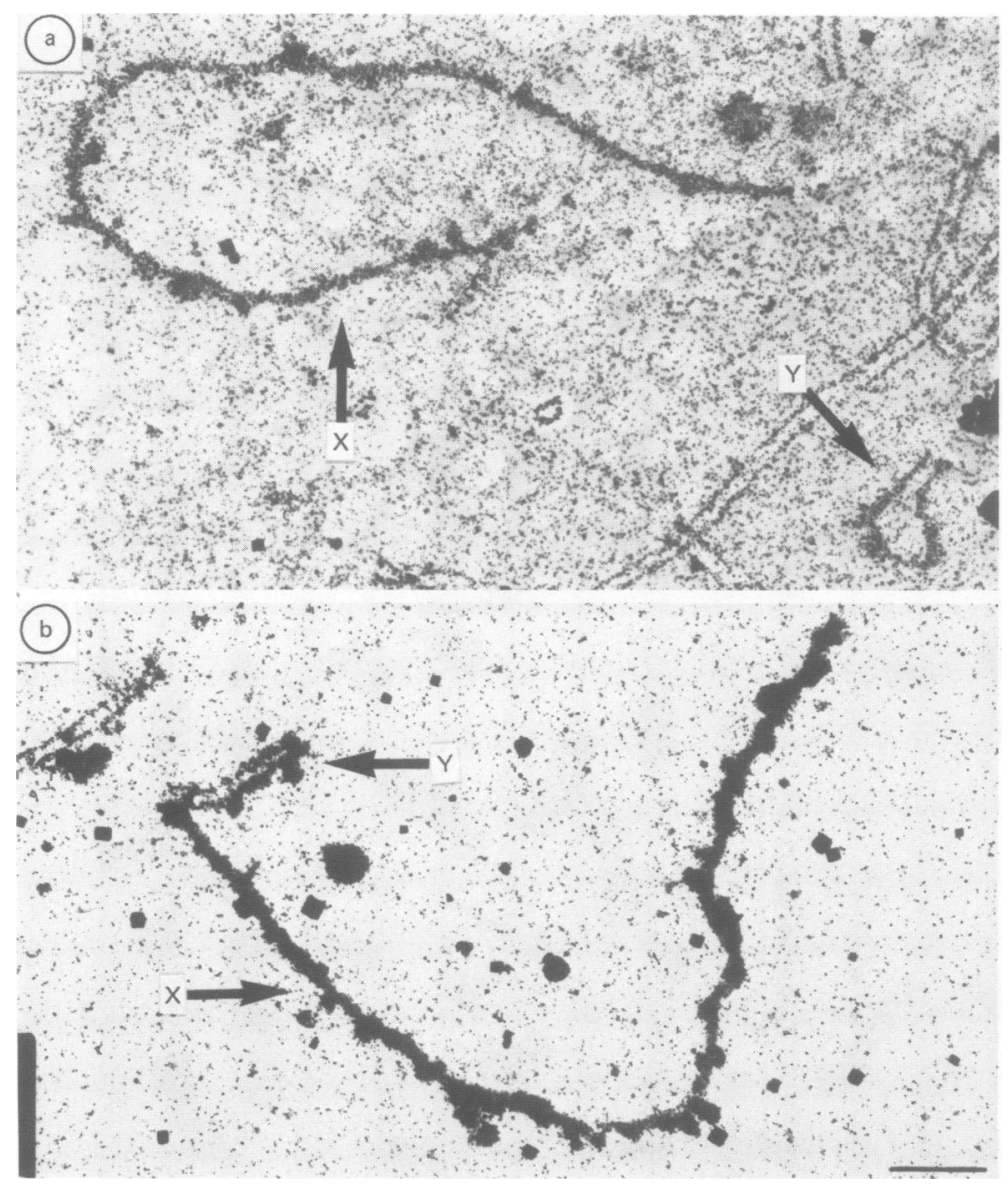

FIG 7 Pachytene spreads stained with silver nitrate. (a) Separated $X$ and $Y$ axes, the $Y$ axis forming $a$ self paired balloon-like structure. (b) Paired $X$ and $Y$ axes, the $Y$ self pairing as a hairpin.

DNA sequences are localised in the constitutive heterochromatin of $15 \mathrm{p}, 22 \mathrm{p}$, and in Yqh. ${ }^{17}$

Some carriers of Yqs chromosomes have been reported with progeny carrying other chromosome anomalies, such as trisomy $21, \mathrm{X}$, iso- $\mathrm{X}$, or $\mathrm{XXY}$, but whether the Yqs has played a role in the origin of these different anomalies is not certain. ${ }^{17} 27$ The present report on our patient and his father would appear to be the first case of structural anomaly in the $\mathrm{Y}$ chromosome of a father with a different structural anomaly in the Y chromosome of his son.

We thank Dr David Page for kindly supplying the probe pDP105, Dr A Busuttil for providing the report on the histology of the testis, and the MRC photographic department for preparing the figures. The technical assistance of Miss $L$ Yorston is acknowledged.

\section{References}

1 Tiepolo L, Zuffardi O. Localization of factors controlling spermatogenesis in the nonfluorescent portion of the human $\mathrm{Y}$ chromosome long arm. Hum Genet 1976;34:119-24.

2 Chandley AC, Ambros P, McBeath S, Hargreave TB, Kilanowski F, Spowart G. Short arm dicentric $Y$ chromosome with associated statural defects in a sterile man. Hum Genet 1986;73:350-3.

${ }^{3}$ Hartung M, Devictor M, Codaccioni JL, Stahl A. Yq deletion and failure of spermatogenesis. Ann Genet (Paris) 1988;31:21-6.

${ }^{4}$ Gallimore PH, Richardson CR. An improved banding technique exemplified in the karyotype analysis of two strains of rat. Chromosoma 1973;41:259-63.

5 Sumner AT. A simple technique for demonstrating centromeric heterochromatin. Exp Cell Res 1972;75:304-6.

6 Dutrillaux B, Viegas-Pequignot E. High resolution R- and G-banding on the same preparation. Hum Genet 1981;57:93-5.

7 Donlon TA, Magenis RE. Methyl green is a substitute for distamycin A in the formation of distamycin A/DAP1 C-bands. Hum Genet 1983;65:144-6.

${ }^{8}$ Denton TE, Brooke WR, Howell WM. A technique for the simultaneous staining of both nucleolar organizer regions and
F

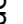


kinetochores of human chromosomes with silver. Stain Technol 1977;52:311-3.

9 Goyanes VJ. Sequential staining of euchromatic and heterochromatic regions of the human Y chromosome. J Med Genet 1980;17:468-71.

${ }_{10}$ Van de Sande JH, Lin CC, Deugau KV. Clearly differentiated and stable chromosome bands produced by a spermine bisacridine, a bifunctional intercalating analogue of quinacrine. Exp Cell Res 1979;120:439-44.

11 Evans EP, Breckon G, Ford CE. An air-drying method for meiotic preparations from mammalian testes. Cytogenetics 1964;3:289-94.

12 Chandley AC, Goetz P, Hargreave TB, Joseph AM, Speed RM. On the nature and extent of XY pairing at meiotic prophase in man. Cytogenet Cell Genet 1984;38:241-7.

${ }^{13}$ Cooke HJ, Schmidtke J, Gosden JR. Characterisation of a human $\mathrm{Y}$ chromosome repeated sequence and related sequences in higher primates. Chromosoma 1982;87:491-502.

14 Distèche CM, Brown L, Saal H, et al. Molecular detection of a translocation $(Y ; 15)$ in a 45, X male. Hum Genet 1986;74:372-7.

15 Gosden JR, Middleton PG, Rout D, de Angelis C. Chromosomal localization of the human oncogene ERBA2. Cytogenet Cell Genet 1986;43:150-3.

${ }^{16}$ Richer CL, Drouin R, Fitch N. Y chromosome R-bands. Hum Genet 1984;67:240.

17 Schmid M, Haaf T, Solleder E, Schempp W, Leipoldt M, Heilbronner H. Satellited Y chromosomes: structure, origin, and clinical significance. Hum Genet 1984;67:72-85.

18 Chandley AC, McBeath S, Speed RM, Yorston L, Hargreave TB. Pericentric inversion in human chromosome 1 and the risk for male sterility. J Med Genet 1987;24:325-34.

19 Andersson M, Page DC, Pettay D, et al. Y;autosome translocations and mosaicism in the aetiology of $45, X$ maleness: assignment of fertility factor to distal Yq11. Hum Genet 1988;79:2-7.

20 Buhler EM. A synopsis of the human Y chromosome. Hum Genet 1980;55:145-75.

${ }^{21}$ Steinbach P, Fabry H, Scholz W. Unstable ring Y chromosome in an aspermic male. Hum Genet 1979;47:227-31.

22 Yunis E, Garcia-Conti FL, de Caballero OMT, Giraldo A. Yq deletion, aspermia and short stature. Hum Genet 1977;39: 117-22.

${ }^{23}$ Devictor Vuillet M, Luciani JM, Carlon N, Stahl A. Anomalies de structure et rôle du chromosomes Y chez l'homme. Pathol Biol 1971;19:231-49.

${ }^{24}$ Chandley AC, Speed RM. Cytological evidence that the Sxr fragment of XY, Sxr mice pairs homologously at meiotic prophase with the proximal testis-determining region.Chromosoma 1987;95:345-9.

25 Speed RM. Oocyte development in XO foetuses of man and mouse: the possible role of heterologous X-chromosome pairing in germ cell survival. Chromosoma 1986;94:115-24.

26 Stahl A, Hartung $M$, Devictor $M$, Berge-Lefranc JL. The association of the nucleolus and the short arm of acrocentric chromosomes with the XY pair in human spermatocytes: its possible role in facilitating sex-chromosome acrocentric translocations. Hum Genet 1984;68:173-80.

27 Joseph AM, Jagannath M, Thomas IM. Yqs resulting from a reciprocal $\mathrm{Y} ; 15$ translocation in the father of a $46, X, \mathrm{i}(\mathrm{Xq})$ girl. Hum Genet 1986;74:203.

Correspondence to Dr A C Chandley, MRC Human Genetics Unit, Western General Hospital, Crewe Road, Edinburgh EH4 2XU. 